\title{
The Aura of the Trace in One Child's Projects in the World: Collecting as Rescue, Repetition, Rupture, and Refrain
}

\author{
Elliott Kuecker and Melissa Freeman
}

\begin{abstract}
Elliott Kuecker is a faculty librarian and researcher at the University of Georgia. He studies research methodology, craft work, and labour. His scholarship can be read in Qualitative Inquiry, International Review of Qualitative Research, Journal of New Librarianship, Library Philosophy and Practice, and other venues. Email: Elliott.Kuecker@uga.edu
\end{abstract}

Melissa Freeman is a professor of qualitative research and evaluation methodologies at the University of Georgia. Her research into philosophically informed traditions has been to understand the variety of analytical strategies used to make sense of the world, to disrupt conventional ways of thinking about research, and to open up new trajectories for research and evaluation. Her most recent book is Modes of Thinking for Qualitative Data Analysis (Routledge, 2017). Email: freeman9@uga.edu

Using one child's archival collection, found in the Prospect Archive of Children's Work at the University of Vermont, we consider the methodological complications involved in attempting to analyze material traces of childhood, created by the child. The experimental school where these artworks were originally completed practiced methods of deep observation and descriptive review of materials collected, rather than sending children's work home. We ponder these pedagogic methods alongside concepts delivered by the German cultural critic Walter Benjamin in order to suggest how the purpose of collecting and presenting traces of childhood can be an act of rescue.
Key words: archives; artwork; qualitative research; Patricia Carini; Walter Benjamin; childhood
Trace and aura. The trace is appearance of a nearness, however far removed the thing that left it behind may be. The aura is appearance of a distance, however close the thing that calls it forth. In the trace, we gain possession of the thing; in the aura, it takes possession of us. (Benjamin, 1999a, p. 447)

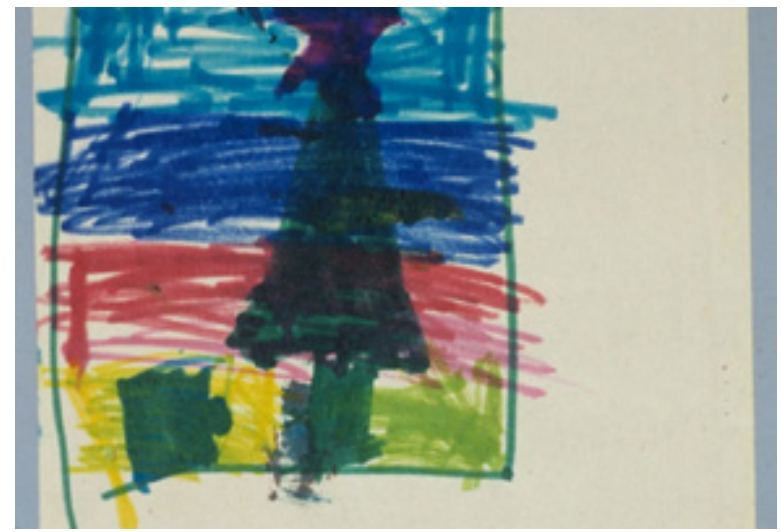

Figure 1. Gus_07010. Source: Prospect Archives and Center for Education and Research.

From 1965 to 1991, the educator and theorist Patricia Carini (1932-2021) ran a small experimental school for children in North Bennington, Vermont, using many of her own pedagogical methods and modes of assessment. Carini's methods emphasized careful observation of children as they engaged in their everyday activities of doing, interacting, acting, making, playing, arguing, and so forth. Resisting the popular developmental models of children of the time, Carini (1979) saw it as her task to see a child "not as a 'case' but as a person" (p. 17). This conviction led her to create several descriptive documentary processes that teachers at the Prospect School carried out for every child. The processes involved collecting children's works, such as their art, written texts, constructions, and crafts, as well as the field notes teachers kept through the day on "the children as they engage in a spontaneous activitythat is, as they play" (Carini, 1977, p. 16).

The drawing introducing this collection is by Gus and is just one of 870 artifacts collected between 1972 and 1980 , 
when Gus was a student at the Prospect School. Creations such as this one were not sent home with children, and nothing got thrown away. Instead, teachers collected everything in "response to the children's passion for making things. A passion expressed sometimes by persistence, sometimes by delight, sometimes by frustration and anger, sometimes by playfulness, sometimes by deep seriousness - and all of these together and more" (Carini, 2011, p. 28). Collecting did not seek to tame these mixed sensations by tidily organizing them, but rather to understand the complexity of children's lived life by gathering all their traces into one place. As Carini (1986) expressed:

To be a child ... is not only to be full of wonder and curiosity but also, in many respects, to be powerlessprey to fears, to the actions of others, and to one's own impulses. Vulnerability and resilience, terror and hope, wisdom and innocence are thus counterpointed in a period of life remarkable for the intensity and the vividness of its experience. (p. 15)

We encountered Gus's drawings in the Prospect Archive of Children's Work at the University of Vermont Libraries, where archivists have arranged and digitized the drawings and writing of many of the Prospect School's students and the related descriptive notes from teachers. These materials show the creative, everyday lives of individual children over several years, offering pedagogues and methodologists an unusual trove of potential "data." The archive as a whole serves as an afterlife of a once-vibrant school, where the material traces, or what Carini (1979) called "a person's projects in the world" (p. 63), help reanimate the school itself.

Our interest in these materials came from, in the first place, a mutual interest in studying children's play and creations, and a curiosity about how qualitative researchers can approach such topics when the child's presence is long gone but their traces remain. Elliott heard of the Prospect Archive upon asking a friend for advice on how to save his preschool daughter's art. She mentioned going to a memorable workshop in North Bennington, Vermont, when she was a schoolteacher in Troy, New York, many years ago. She recalled everyone sitting in a circle and closely studying a single piece of art, only to learn that the Prospect School teachers kept everything created by all the children. Quickly, Elliott was able to locate the archive of the school from the clues available and mentioned it to Melissa, given that she had lived in Bennington for so long. Melissa did not know that the archive was being held at the university, but her life had crossed with Pat Carini's in many ways: as a Bennington College student of Carini's husband, Lou, years later as a hopeful researcher at the Prospect School during her graduate studies, and as an admirer of her work.

Together, we studied the artifacts in the collection and read Carini's articles and books, only to find that our conversations always came back to methodological conundrums in trying to figure out how one set of researchers could operate within another researcher's (Carini, in this case) collection. We wanted to do what Carini was after and bring life back to childhood by attending to these artifacts. In our selections of different artworks to include in our study, theorists we wished to cite, and specific portions of Carini's concepts on which we wished to draw, we found that we were not really bringing life back to childhood at large, or even to the Prospect School. We were only bringing life to our own new collections, and therefore could not say much about the Prospect School, the children, or anything within its original context. There are problems in representing childhood, individuals, or education through fragments of evidence (or any evidence for that matter). For us, the inability to represent something or someone on the basis of any evidence, no matter how comprehensive a collection of data we believe we have actually obtained, is not actually a problem as much as being a worthy methodological discussion about the intersections of collecting and researching. Rather than simply problematize the tradition of representation, we ask: What can coming to research as a collector of fragments rescued from the past offer?

The collector has a "very mysterious relationship" (1999c, p. 487) to the objects collected, wrote Walter Benjamin (1892-1940), the German theorist known for his many amateur collections of books, toys, postcards, and quotations, 
among other things. He added that the true collector "does not emphasize their functional, utilitarian value ... but studies and loves them as a scene, the stage, of their fate" (p. 487). Benjamin viewed the act of collecting objects as a way to create a scene, set a stage, or determine a new fate, a useful insight that seems to give the collector the power of creating life. Weaving themes from Benjamin's writing and Carini's educational theories-rescue, repetition, rupture, and refrain - we illustrate a way to see collecting as a worthy research mode, particularly in the context of studies of the everyday life of children. To keep the child present in the work, we have integrated Gus's artwork in ways that seem to argue with or aid our points.

\section{Rescue}

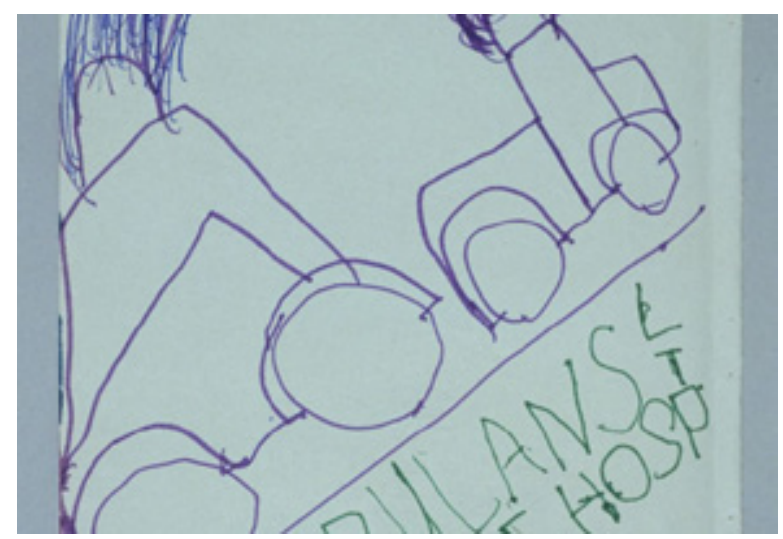

Figure 2. Gus_08_044_4. Source: Prospect Archives and Center for Education and Research.

In Carini's method, the objects collected and the notes created during the week form the basis for the "descriptive review," a weekly collective process led in turn by each teacher focused on a particular child around puzzling questions. For example, a teacher might ask: "How is it ... that this child seems always to slip by me? How can I get a clearer picture of where she is making her presence felt in the group?" (Carini, 2000, p. 13). The presenting teacher would share their notes on the child and invite the others not only to reflect on each selected piece of the child's work but to follow the question as well, brainstorming the various meanings of "slip" and "slips" (Carini, 2000 , p. 13). Everyone in the room would then describe what they saw in the artwork or text presented, being mindful to never focus on what was missing, always remaining respectful to the child. The power of this review was the attention given to each detail, the focus on a single student and the singularity of each work, far from the bustle of daily classroom life.

Carini had this penchant for deep description of quotidian life in common with Benjamin, who is most known for his masterpiece, The Arcades Project, a large volume made almost entirely of collected scraps of other writers, in German, French, and English, organized thematically. He wished to include so many details that he miniaturized his handwriting in order to fit as much as possible into his notebooks. These collections were so dear to him that upon facing exile during Nazism, he sent them off to friends for safekeeping so that the Nazis could not destroy them, exhibiting his desire to rescue cultural objects from oblivion. Hannah Arendt (1968) would explain his method, writing, "collecting is the redemption of things which is to complement the redemption of man" (p. 42).

Benjamin, like Carini, saw observing as similarly central to research. He famously elevated the concept of walking research in his image of the flâneur, taken from the French writer Baudelaire. The flâneur, for Benjamin (1999b), was "the priest of the genius loci ... [an] unassuming passer-by, with his clerical dignity, his detective's intuition, and his omniscience" (p. 264). The flâneuse is not concerned with tourist traps or walking by the birthplaces of 
idols, but rather ponders the "single weathered threshold or the touch of a single tile-that which any old dog carries away" (1999b, p. 263). Idle observation of even the most profane of details was an important act of research for Benjamin, inspiring Arendt (1968) to say that Benjamin's flâneur was capable of catching the "secret meaning" of things (p. 12). Once gathered, his observations and objects would be arranged in order to be rescued back to life within a magical, "charmed circle of fragments" (Benjamin, 1999b, p. 446).

Carini similarly saw her collections as acts of construction in which objects and observations formed a tapestry of each student's life. Over time, these tapestries actually validated not only that one child's life but the importance of childhood in general, bringing visibility to a child's own "organization of reality at different ages" (1977, p. 16). Collecting the children's work provided evidence for each life's unique patterns of continuity and transformation (Carini, 1979). Carini's method acknowledged the way different people and different age groups operate within different, and yet valid, realities. Likewise, Benjamin claimed that when the past, present, and future are brought into communion through collections, the collector is able to disrupt any idealized organization of reality and "experiment with a discontinuous form of representation" (Kany, 1990, pp. 328-329). Conventional historical methods often weave evidence to create an illusion of factual and singular representations of events and people, while Benjamin's mode emphasized the way society is "completely fragmented and derivative" (Benjamin, 1996, p. 39). When we experiment with forms of presentation that move beyond representational thinking and offer different versions of reality, the fragments in a collection form a disruptive force that reveals something new.

Benjamin and Carini shared an interest in rescuing the reality of children from immanent destruction, which, for both, was a small world within a larger one. For example, in one text Carini relays an observation while watching children interacting with ant piles. The children build mazes for the ants with little sticks, and one child sings "Mrs. Ant" as she works. Carini (1977) realizes that, "in miniature, exists a whole world, a world as the child has constructed and represented it" (p. 15). She described how she was drawn to collecting scraps of work children left behind because of the power of the work itself (Himley, 1991). Besides the many questions these materials raised for educators, Carini recognized the value of collecting itself, and archive boxes were placed in each classroom "for children to submit works for their own files" (Himley, 1991, p. 32).

Through years of observation, Carini recorded how children interacted with materials that the school provided, or objects children found on their own. She noted that engrossment with materials revealed the child's unique ways of relating to things. She reported about one child, Jack, for example, that his gestures and movements were only meaningful as viewed in relationship to

things-books, trees, persons, rockets, balls-and in the context of the pervasive orientation or perspective of his body, which is toward things, in reaction to them, and in anticipation of them. (Carini, 1979, p. 56, emphasis in original)

Carini writes here that the relationship between the child and the object is reciprocal, as the child does not merely act against or with the object but responds to it, anticipates its next move, creating worlds by coconspiring with each object. Benjamin would similarly observe the child's interest in materials, suggesting not only that these materials were already alive but that children gave them renewed lives through their processes of collecting and arranging: "A bit of wood, a pinecone, a small stone-however unified and unambiguous the material is, the more it seems to embrace the possibility of a multitude of figures of the most varied sort," noted Benjamin (1999b, p. 115). It was in these unions of surprising materials that Benjamin saw the life-giving magic children offer inanimate things (Benjamin, 1999b).

Carini's desire to keep children's creations acknowledged the ways children have great agency as makers, 
experimenters, and producers. Providing spaces and materials for children, and carefully collecting and observing what is produced, Carini was able to salvage bits of childhood and make visible things that were hidden from those who did not carefully look at or acknowledge children's ways of being. This way of thinking of children overlaps with Benjamin's general interest in the quotidian. He saw the value, not in grand narratives and major events, but rather in minutiae, making "the chronicler" (Benjamin, 2003, p. 390) a person of great import.

The concept of rescue, then, comes from the way in which Carini and Benjamin saw collecting as a life-giving method which takes an original moment and puts it into new arrangements, creating new contexts and meanings along the way. Moments put together form a collection, and these collections offer a literal "rebirth" (1999c, p. 487), to use Benjamin's term. In contrast to a nostalgic worship of the past, Pfeifer (2018) describes this sensibility in Benjamin as a "Noah-esque impetus to preserve," wherein he "acts as an ethnographer who seeks to save indigenous cultures by documenting them" (p. 51). But unlike the ethnographer, Benjamin was not collecting indigenous cultures but rather moments and objects from everyday life, such as toys, books, quotations, and photographs. For Carini, what is collected is a child's presence in the world, their artwork, writings, moments at the ant pile, interactions with a ball, and so forth. These small things exist all around us as traces, which Benjamin (1999c) saw as "the primal phenomenon of all the habits that are involved in inhabiting a place" (p. 473).

Importantly, however, the concept of rescue also suggests the idea of urgency and the risk of loss. There is a darkness to the concept of rescue, and it is no surprise given that Benjamin was grounded in the context of the rising Holocaust, where losses of both literal and figurative childhood plagued millions of Europeans. But all childhoods, like the many Carini witnessed as an educator, are temporary. Carini seemed to dwell in this understanding, choosing to keep traces of childhood to later create those tapestries of each child in a kind of rebirth through material.

In looking through the collection of art and writing from Gus, we realized that what we are able to say or understand about Gus exists more on the affective level than anything else. All data collection strategies offer unique challenges and prospects. Analyzing the traces left by Gus likely says more about our own preconceptions and preoccupations than anything about the actual Gus. His pictures show burning chimneys and green mountain landscapes, which suggest Vermont in the 1970s. There are many drawings of houses, often standing alone or in pairs, many with invisible walls so we could see the staircases inside, or colour blocked so that each level or section was coloured in with a different colour. There are also a few drawings involving figures or rescue vehicles of different sorts. There are pictures of a stabbing and a car accident, ambulances and blood. All we could do was pile on questions and wonder about his interest in houses, his use of colour, his choice of subject matters. Had there been a stabbing in Vermont that year? Had he seen an actual rescue or watched one on the news with his family? Had he been asked to draw a holiday scene or did he just choose to draw a big Christmas tree with a star on top? What materials were available to him?

These questions get at something that Benjamin and Carini both knew regarding the life of objects. We were not merely there to interpret them, but they were actually summoning us, taking hold of us as we enlisted them into our collection. We selected drawings of Gus's work, trying to deem what was worthy to discuss among the hundreds of available items, knowing that what we selected would be what was "rescued," at least for the moment. In a review of studies looking at this phenomenon, Russell Belk (1988) explained: "Apparently, in claiming that something is 'mine', we also come to believe that the object is 'me"' (p. 141). The objects that people collect are not separate entities in the world, inanimate and given value only in their use. In this light, it makes sense to look at a piece of artwork or a collection of objects as a kind of evidence of another's being. It also sanctifies the objects, even small collections of pinecones, as sacred enough to be worthy of keeping, which is precisely what Carini 
did by archiving the children's works. Attaching this kind of power to objects seems intuitive, given that most of us have experiences where "things provoke thought, incite feeling, circulate affects, and arouse in us a sense of wonder" (Barnett \& Boyle, 2016, p. 1). But more complicatedly, as Benjamin suggested in saying things can "gaze back," objects do not exist purely for human use: "They are also vibrant actors, enacting effects that exceed (and are sometimes in direct conflict with) human agency and intentionality” (Barnett \& Boyle, 2016, p. 1).

In conventional research, we might try to find the individual child through the drawings and teacher accounts left behind - traces of productivity, living, practicing life-but what assumptions lurk beneath this move? What does it say about how meanings circulate when we assume that what we make is a part of us, represents something about us, is us? And isn't this what we are always assuming when we "collect" data, any data? Isn't the question of our relationality to past, present, and future precisely what our encounters with Gus have opened? Working against the Carini method now, where we might have been able to create a tapestry, we could not say much about Gus in a representational way, particularly given that these images contradict each other and any argument we formed eventually proved wrong. The artifacts, it seems, do not only gaze back but try to argue. This is perhaps suitable, as Benjamin (1999c) proclaimed: "For what else is ... [a] collection ... but a disorder to which habit has accommodated itself to such an extent that it can appear as order" (pp. 486-487). Composing any kind of coherent narrative about the collection brought out the "dialectical tension between the poles of disorder and order" (Benjamin, 1999c, p. 487). Instead, we simply cherished the distinctive auras, "standing ... with our ears open and listening" (Vilhauer, 2010 , p. 54) to what kind of new life our little collection was conjuring.

\section{Repetition}

Through memory, the person as the carrier of meaning is indeed kin (both as a time and as a person) to other times. Thus, whatever it is the person seeks to know, it lies within his own meaning and time, and also it lies in the meaning and time that have preceded his existence and are now passing through him. (Carini, 1979, p. 61)

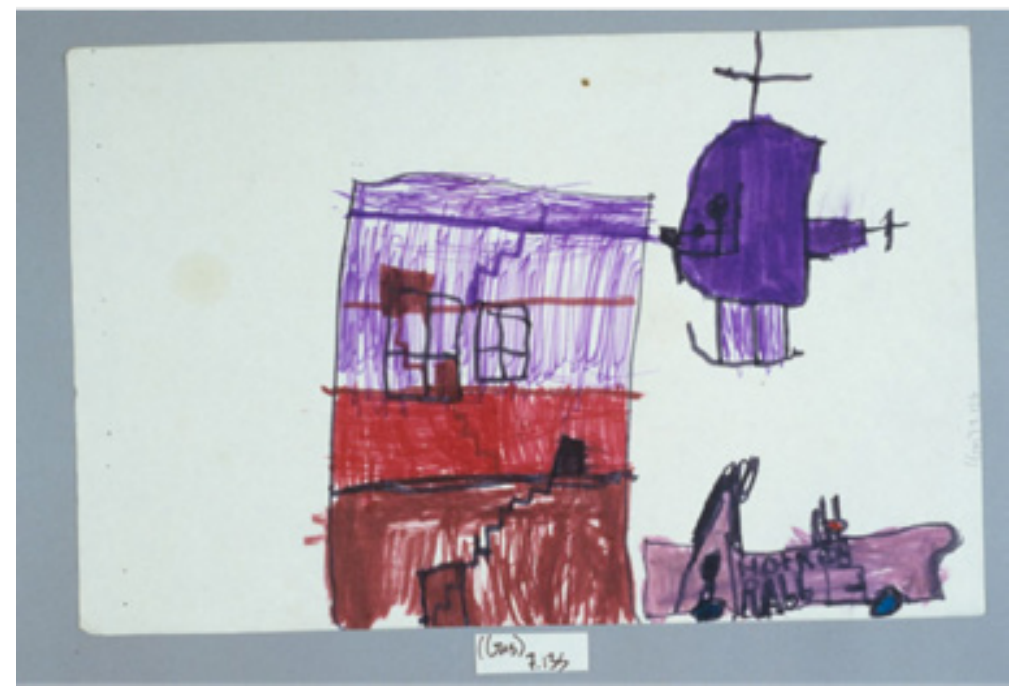

Figure 3. Gus_07_135. Source: Prospect Archives and Center for Education and Research.

While Carini and Benjamin both believed in the careful process of conducting repeated observations, collecting numerous fragments of material over time, they also believed that history should not be repeated but changed, as is evident in the concept of rescue. For them, repetition was not an empty gesture but carried along with it a formidable ethical responsibility. For changed understandings to occur, new adaptations of old methods were 
necessary. Each in their own way believed that the kinds of chance encounters that might spark new insights required habits of observation, documentation, and description. "Good history," noted Friedrich Nietzsche (as cited by Pfeifer, 2018, p. 50), "does not preserve [bewahren] life, but rather, generates it [zeugen]." Reflecting on the development of her method, Carini (2000) wrote that "the design of the multifaceted inquiry" she and the teachers at the Prospect School practiced must "focus on process" (p. 9, emphasis in original). The process was one in which ongoing observation of "the child in motion" would allow the teacher "to adjust her or his own approaches to the child accordingly" (p. 9, emphasis in original). In this way, even the repetition of attention toward the same child was done for the sake of changing the future ways of relating to and teaching that child.

Equally, in looking at Gus's artwork as it stands today, we find that it is better to attempt to understand it in its current context, as one of the repetitions of its existence. The helicopter, car, and building may have represented something for Gus when he first illustrated them, but in thinking with the concept of the "child in motion," it seems more useful to view this illustration as it stands now in its new life, rather than go chasing after representations we could never really know. Carini's drive to see a child in motion was based on this faith in repetition, which she saw as a necessary element of life: "Recurrence is the thread that holds the life fabric.... However, if recurrence maintains the fabric, choice is the thread that transforms the recurrence from empty repetition into a vivid pattern or tapestry that displays a lived destiny" (1979, p. 9). Benjamin (1999b) similarly assumed that repetition was a life-giving act rather than an empty practice. He asserted that "repetition is the soul of play" (p. 120). By doing "the same thing again and again ... a child creates the entire event anew and starts again right from the beginning" (p. 120).

In Carini's daily life at the Prospect School, she would have had enough to observe for many lifetimes, particularly because of the nuance of her observations. In collecting details of the children, for example, she attended to medium, which for her "refers to the material or form in which a motif is treated such as paint, clay, blocks, sand, or writing ... [as well] as play, reading, and thinking" (Carini, 1979, p. 62). In attending to medium, the observer could refer back to their notes and rework them over time to find the recurrences and motifs in the children's activities. Carini (1977) believed that we can learn a lot about the value of a thing by thinking carefully about it through descriptive writing, which will then serve as a textual source for hunting down patterns of repetition that have been noticed over time.

In this way, again, Carini and Benjamin shared an approach. Benjamin did not work in a school but instead walked through many European cities, sometimes for travel and often as refuge during exile. He is said to have repeated his walks in the same cities so often that he had to make maps in order to get lost and create new repetitions. He, too, oriented himself toward the nuance of the routines of the day and recorded his observations in notebooks. McMurtry (1999) thought this was Benjamin's strongest mode of research, saying he "was best when composing a kind of critic's notebook, in which he let his intelligence play over what he saw and smelled, whether a new city or a new book" (p. 184). While both the schoolhouse and the city street make up quotidian aspects of life, both Benjamin and Carini understood their projects to be interventions to the status quo, with the goal of impacting the world of the future.

Finding instances of repetition helps locate motifs and patterns. Carini's belief that a child's material traces form a fabric of life is only possible when recorded moments are curated in ways that reveal patterns of repetition and difference (Carini, 1979), offering the possibility of putting singular instances together into arrangement. An idea like this matches well with Benjamin's interest in the Jewish mystical tikkun, a concept that suggested the "vessels of God's attributes were broken and this breaking of the vessels scattered divine sparks in fragments throughout the material world" (Leslie, 1998, p. 12). Collectors of the fragments were seen as responsible for the messianic task 
of putting the fragments back together and recreating the vessel. Gathering the repeated pieces scattered across many lands and then putting them back together was "a task both secular and divine. Much like the meshing of shards of montage, or the restorative practice ... the world is to be put back together" (Leslie, 1998, p. 12).

It seems that Carini saw the gathering of fragments as a kind of messianic action, particularly given that her method of observation had a devotional quality to it. Writing and observing constantly, Carini seemed to collect as if life depended on it, as if some kind of rescue were at stake. Carini (1979) wrote, "The act of writing keeps the observer focused and attentive, although if the recording should dominate seeing, then the record would limit the observation rather than intensify it" (p. 45). In addition to the labour of attention toward both recording and seeing, she also labelled and preserved the creations of each child. She was practicing the professional archivist's task of arrangement and description, creating an ever-growing storage space in a small, little-known school. Coming to the archive as a researcher today, an uncanny kind of force takes over where one must track that work, trace ideas, and create a record of the connections from the artworks to personal readings. Very quickly, the role of description falls into the lap of anyone looking at Carini's collection, as a strange repetition of duty.

Order, it is no wonder, is not easily achieved when dealing with tons of fragments. Benjamin (1999a) wrote, "For the collector, the world is present, and indeed ordered, in each of his objects. Ordered, however, according to a surprising and, for the profane understanding, incomprehensible connection" (p. 207). In other words, the strings that connect one thing to another are subjective, tricky, and sometimes unconscious things. Made from observations like those of the flâneur, a city-walker who "moved freely in all directions on the societal grid[,] Benjamin's ventures always represented approaches to the threshold, the Other, the forbidden" (Birkerts, 1982/1983, p. 169). The flâneuse does not have a destination, or an easily traceable trajectory, but rather the freedom to cross familiar and unfamiliar terrains. Disobeying a sense of order allows for unpredictability, where flashes of insight are provoked, moments of recognition amidst the comatose actions of humankind.

Benjamin's words act as caution for us to not rely upon typical orientations to objects, but instead to seek new perceptual relationships, an idea Carini (1979) also explored. Qualitative methodologists are most likely already familiar with this need for creating perceptual relationships beyond the clichéd connections and conclusions that merely repeat the world as it is. Renewing it, changing it, would have to break some repetitious connections, giving research the power to summon us to take seriously the relationships between the methodologies we employ and the worlds we are, and envision, curating (Kuntz \& Pickup, 2016). Patti Lather (2001) offers the wisdom that "the task is not whether to repeat but how to repeat in such a way that the repetition displaces that which enables it" (p. 204), a task which Gus seemed to perform well. 


\section{Rupture and refrain}

Benjamin ... dismembers as in a mortuary; he too creates new contexts, and imparts new meanings. (Kany, 1990, p. 328)

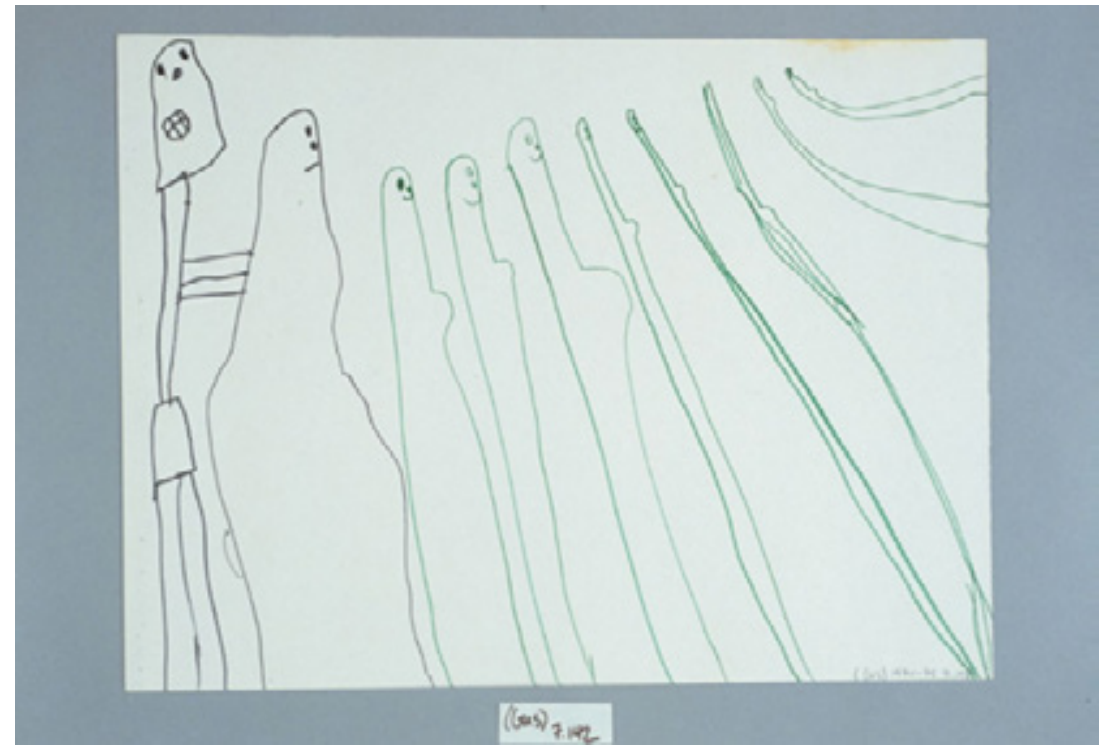

Figure 4. Gus_07_142. Source: Prospect Archives and Center for Education and Research.

Gus's artwork helps make the point that it is difficult to address the work of others. Unbeknownst to Gus, this drawing, like the others, keeps us questioning and continues to shape our thinking. For example, what could we possibly say about this strange group of figures facing sideways except for the one on the far left? We could compare it to other figures in Gus's collection. We would soon realize, however, that even if there were similarities to note across drawings we could not interpret these in the sense of trying to understand what they might mean or represent. But this does not mean they are not worthy of our contemplation, that they do not offer us much to consider, unmoored as they are from any context. Looking more closely at this picture, can we even call it a group? Might it not be the same figure mutating or moving across and out into the distance? Or perhaps they are marching off to extinction, a ghostly voyage towards an unknown destiny. Like Gus's figure on the left, we grit our teeth and allow ourselves to be transformed.

Carini and Benjamin shared a belief in the transience of objects and the need to rescue them because of the way objects pointed to historical meanings that risked extinction. For Carini, the loss was that of childhood, a childhood that symbolized more for humanity than the life of children. For Benjamin, the loss was the movement of allegorical understanding (Kany, 1990), unique insights scattered across multiple landscapes. We too are moved to bring out of the past images, philosophies, and strategies that help us further Carini and Benjamin's efforts to disrupt.

How do we collect materials from the past and present to rupture static and preconceived understandings clogging our systems of meaning? Marx and colleagues (2007) describe Benjamin's approach:

Benjamin repeatedly treated the elements of his text according to the principle of building blocks: he copied them out, cut them out, stuck them on new sheets of paper and arranged them anew, long before such procedures became established in electronic word-processing under the name "copy and paste." ... Benjamin's idea of composing a work entirely out of quotations ensures that the material 
within the collection can remain mobile, elements can be shifted at will. At the outset all material is of equal value: knowledge that is organized in slips and scraps knows no hierarchy. (pp. 93-94)

Benjamin was fascinated by artists who disrupted the norms of art, particularly people like Paul Klee, who purposely drew like a child. Benjamin's own archives are replete with examples such as casting a piece of paper into the wind hoping it will reveal the plot for a novel, a fragment that itself was taken from an account quoting another source altogether (1999a, p. 441). Other influential sources for Benjamin were children themselves, who are known to collect flotsam and jetsam and put them together in novel ways. For Benjamin, young children have a kind of genius in their propensity to enliven odds and ends, naming them as if they were live beings, endlessly creating, or as Carini called it, making. This creating is to be taken seriously, as Benjamin found in it a potential "to renew the old world" (p. 478). Elsewhere, he noted that children reveal through gesture "a signal from another world, in which the child lives and commands" (Benjamin, 1999c, p. 204) and which, he said, is the future to come.

Like many of ours today, Benjamin's research context was urgent-from the mundane struggle to pay rent to the grand struggle to survive the Holocaust (he didn't). His concerns remind us of other scholars who have found themselves moved by the important, ethical task of their work. At the same time, so many of these researchers found it challenging to create a world of meaning with minoritized perspectives without subsuming them into preconceived discourses. For example, Lather and Smithies' (1997) book Troubling the Angels: Women Living with HIV/AIDS split the text horizontally creating juxtaposed accounts of the experiences of women living with HIV/ AIDS while also including intertextual matter, in this case, images and textual fragments about angels. Speaking to the readers directly, the authors explain that angels helped them provide "a reversal of the 'demonizing' attitudes that many have towards people with HIV/AIDS" and act as "bridges between worlds" (p. 48).

Collecting angels in their different forms across time and disciplines created a refrain, a space in-between chapters that provided a break from the devastating accounts of the women while also deepening a sense of responsibility towards them and prompting a collective fight against the disease. As Lather and Smithies explain: "These are angels who trouble our sense that all is right with the world, that AIDS is something 'out there', unrelated to each one of us, and from which we can afford to distance" (p. 230). Twenty years later, Maggie MacLure (2016) also conjures the "refrain" - to interrupt the flow of meaning, cause a rupture in the plot, and create a break in the logical order of language. Repetition, refrain, and rupture are practices of the collector as well as the researcher, practices that, for better or worse, we cannot not engage in.

The collector has the power-and thus responsibility-to rearrange pieces of the past, whether or not they see themselves doing historical work. We are not interested in the view of collecting that emphasizes forms of commodity fetishism but rather the kind of collecting that brings out critical appropriation, or really, critical appraisal, critical selecting, and careful reappropriation. If we can gather what is worth keeping and put it into new circles, we might create a world that does away with that which should not be kept. As Kuntz and Pickup (2016) write, "To be critical one must work towards truth-claims that disrupt the normative flow of common-sense; critical work cannot replicate what is already known" (p. 172, emphasis in original); neither, however, should this process overlook the way the things themselves carry the past within them.

We hope our paper demonstrates that research is often a kind of collecting that leads to creating and rescuing. As such, it is fraught with ethical tensions, detours into the unknown, problematic connections that need revising, and it requires the help of the multitude of objects scattered throughout historical landscapes, many of which remain elusive and inaccessible. In other words, it requires an understanding of the way all things, past or present, have material effect on our understandings. Benjamin often tried to dialogue with objects and things from the past through his use of the "generic" term aura "to denote ... the enigmatic within the other: the simultaneous 
manifestation of sameness and difference" (Loveluck, 2011, p. 182). What really makes something a work of art, according to Benjamin, is its "capacity to engage in dialogue with the onlooker, to return the gaze since there is something essentially human about them" (p. 182). The capacity to dialogue and gaze back is heavy in Gus's individual works, and made much heavier by Carini's accumulation and volume, granting it a substantial aura.

Collecting, researching, writing, then, are all part of world-creating processes, where life is given. As Benjamin said, that is indeed a kind of child's play. This, of course, is not a new idea but one that is often stripped of its seriousness. What we are interested in here is a kind of experimentation that is redemptive and messianic. This kind of experimentation, or play, is not without risk, and cannot prevent us from doing harm along the way. Nevertheless, we must keep ourselves "in play" (Vilhauer, 2010, p. 55, emphasis in original), attuning ourselves to “"troublesome' moments as indicators of the potential for creation” (MacLure, 2016, p. 180), while learning from "the refrains of children [as these] attest to the interconnections of mind and body, of sounds, matter, affects, words, and thoughts" (MacLure, 2016, p. 180).

\section{The aura of the trace: On being (critically) enchanted}

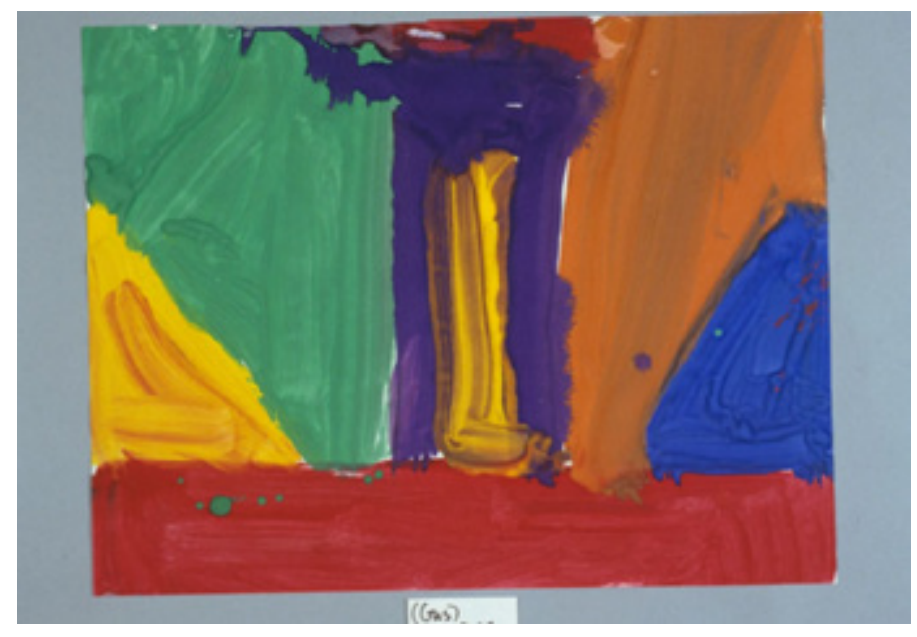

Figure 5. Gus_08_057. Source: Prospect Archives and Center for Education and Research.

We believe that the collector's sensibility found in Carini's and Benjamin's work offers a methodological approach that speaks to the need for renewed ethics, requires reflection on our work as researchers, collectors, and writers, and demands a relentless concern for the state of things. Carini and Benjamin reveal the way in which this sensibility can work in any circumstance, whether it be in the midst of one of humanity's greatest disasters or in the midst of small-town-elementary-school life. Both worked to collect in order to rescue something deeply important and then to use it as a generative force for the new. Each avoided treating collections as evidence for some grand claim, bypassing what Lather (2001) calls "historical sedimentations" (p. 200) which act to preserve $a$ truth that will go on to be circulated nearly invisibly. Opposing this view, Carini and Benjamin preserved as forms of intervention, making fragments and traces that critically reappropriated parts for the creation of something better, something still within possibilities-to-come. In following their ethics directly, we see that historical sedimentations, or grand narratives, are replaced with more messianic conjuring.

In trying to understand how one goes about "rescuing" objects without reinscribing them with similarly unjust meanings, we realize that operating with a purely critical sensibility merely shines light into darkness, illuminating what one wishes to show and leaving the rest in the dark. These ethics don't match the critical mode of Carini and 
Benjamin, who used criticality to make note of what needed their attention-childhood realities, the agency of making, the freedom to walk through the city. Each, in their own way, wrote urgently on the power of the insights generated through careful observations to speak back to the destruction of ways of being, some of which have never historically had a chance to fully materialize. Each also understood that creation of things to come required attentiveness to re-collection as well as collection, that one of neoliberalism's effects is to separate models, such as, for example, the scientific method from the discursive contexts in which it was created and debated (Carini, 1979). The present and future should not be reconstrued without also accounting for these often competing effects. This is not a call to return to an original, either in regards to historical context or in regards to the objects collectedneither Carini nor Benjamin believed in the possibility of representing an original context or object-but one that points to the gravity of our work as collectors and composers. Regardless of our intent, we are always folding the past into the future; our games are not frivolous.

When we build a new world on and with some of the ruins of the old, we get to decide what stays. Benjamin (2003) warned, if we don't, the enemy will do it on their own, folding traces and fragments into their own schemes, which will already be sedimented when the flood comes to take the rest away. The long, slow devotion of attention toward things and the rescue of some things in our acts of creation mean that each one of us partakes in this messianic power (Benjamin, 2003).

Beyond the theoretical matters of this approach, there is a great simplicity to enacting it. Carini and Benjamin both believed that their work required habits of careful observation, documentation of everyday things and activities, and detailed description. They both drew inspiration from the habits of children, relying on children as teachers of method as much as subjects of study. And as we have shown, in both of their work there is an encouragement to be open and attuned to seeing things afresh, much as the child does. This is not a romanticizing vision of the child and childhood but an acknowledgment of the value of the play of creation, not for play's sake but as a form of negating the world as it is, for worlds that could be.

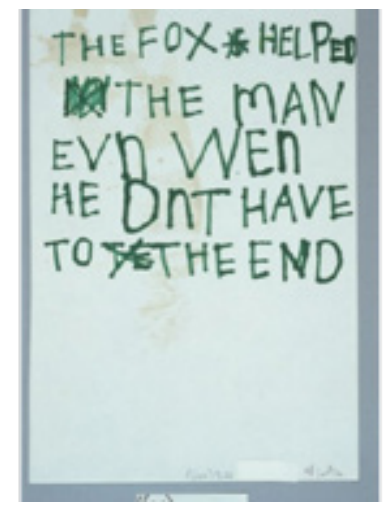

Figure 6. Gus_09_021. Source: Prospect Archives and Center for Education and Research. 


\section{References}

Arendt, H. (1968). Introduction. In W. Benjamin (Author) Illuminations: Essays and reflections (pp. 1-55). Schocken Books.

Barnett, S., \& Boyle, C. (2016). Introduction: Rhetorical ontology, or, how to do things with things. In S. Barnett \& C. Boyle (Eds.), Rhetoric, through everyday things (pp. 1-14). University of Alabama Press.

Belk, R. W. (1988). Possessions and the extended self. Journal of Consumer Research, 15(2), 139-168. https://doi.org/10.1086/209154

Benjamin, W. (1996). Selected writings, Volume 1, 1913-1926 (M. Bullock \& M. W. Jennings, Eds.). Harvard University Press.

Benjamin, W. (1999a). The arcades project (H. Eiland \& K. McLaughlin, Trans.). Harvard University Press.

Benjamin, W. (1999b). In M. W. Jennings, H. Eiland, \& G. Smith (Eds.), Walter Benjamin selected writings, Volume 2, part 1, $1927-1930$. Harvard University Press.

Benjamin, W. (1999c). In M. W. Jennings, H. Eiland, \& G. Smith (Eds.), Walter Benjamin selected writings, Volume 2, part 2, $1931-1934$. Harvard University Press.

Benjamin, W. (2003). In M. W. Jennings, H. Eiland, \& G. Smith (Eds.), Walter Benjamin selected writings, Volume 4, 1938-1940. Harvard University Press.

Birkerts, S. (1982/1983). Walter Benjamin, flâneur: A flanerie. The Iowa Review, 13(3/4), 164-179. https://www.jstor.org/stable/20155922

Carini, P. (1977). Building a curriculum for young children from an experiential base. Young Children, 32(3), 14-18.

Carini, P. F. (1979). The art of seeing and the visibility of the person. University of North Dakota Press.

Carini, P.F.(1986). Building from children’s strengths. The Journal ofEducation, 168(3), 13-24.https://doi.org/10.1177002205748616800304

Carini, P. F. (2000). Prospect's descriptive processes. In M. Himley \& P. F. Carini (Eds.), From another angle: Children's strengths and school standards. The Prospect Center's descriptive review of the child (pp. 8-22). Teachers College Press.

Carini, P. F. (2011). Collecting and describing children's works at Prospect (rev. ed.). In L. Strieb, P. Carini, R. Kanevsky, \& B. Wice (Eds.), Prospect's descriptive processes: The child, the art of teaching, and the classroom and school (pp. 27-29). The Prospect Archives and Center for Education and Research.

Himley, M. (1991). Shared territory: Understanding children's writing as works. Oxford University Press.

Kany, R. (1990). Particularism in the work of Walter Benjamin. Criticism, 32(3), 325-341. https://digitalcommons.wayne.edu/criticism/ vol32/iss $3 / 4 /$

Kuntz, A. M., \& Pickup, A. (2016). Critical inquiry for the social good: Methodological work as a means for truth-telling in education. Critical Questions in Education, 7(3), 171-177. https://files.eric.ed.gov/fulltext/EJ1114643.pdf

Lather, P. (2001). Postbook: Working the ruins of feminist ethnography. Signs: Journal of Women in Culture \& Society, 27(1), $199-227$. https://doi.org/10.1086/495677

Lather, P., \& Smithies, C. (1997). Troubling the angels: Women living with HIV/AIDS. Westview Press.

Leslie, E. (1998). Walter Benjamin: Traces of craft. Journal of Design History 11(1), 5-13. https://doi.org/10.1093/jdh/11.1.5

Loveluck, B. (2011). The redemption of experience: On Walter Benjamin's "hermeneutical materialism." Philosophy and Social Criticism, 37(2), 167-188. https://doi.org/10.11770191453710387069

MacLure, M. (2016). The refrain of the a-grammatical child: Finding another language in/for qualitative research. Cultural Studies <-> Critical Methodologies, 16(2), 173-182. https://journals.sagepub.com/doi/10.1177/1532708616639333

Marx, U., Schwarz, G., Schwarz, M., \& Wizisla, E. (Eds.). (2007). Walter Benjamin's archive: Images, texts, signs (E. Leslie, Trans.). Verso. 
McMurtry, L. (1999). Walter Benjamin at the Dairy Queen. Simon \& Schuster.

Pfeifer, A. (2018). A collector in a collectivist state: Walter Benjamin's Russian toy collection. $\quad$ New German Critique: An Interdisciplinary Journal of German Studies, 45(1), 49-78. https://doi.org/10.1215/0094033X-4269850

Vilhauer, M. (2010). Gadamer's ethics of play: Hermeneutics and the other. Lexington Books. 